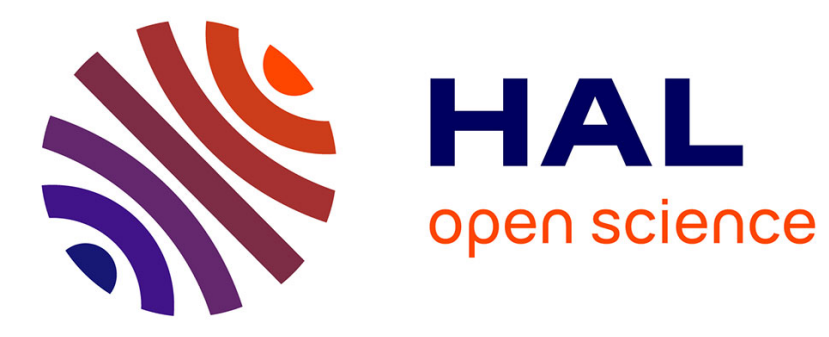

\title{
Sen is not a capability theorist
}

\author{
Antoinette Baujard, Muriel Gilardone
}

\section{To cite this version:}

Antoinette Baujard, Muriel Gilardone. Sen is not a capability theorist. Journal of Economic Methodology, 2017, 24 (1), pp.1-19. 10.1080/1350178X.2016.1257821 . halshs-01885065

\section{HAL Id: halshs-01885065 https://shs.hal.science/halshs-01885065}

Submitted on 7 Jan 2019

HAL is a multi-disciplinary open access archive for the deposit and dissemination of scientific research documents, whether they are published or not. The documents may come from teaching and research institutions in France or abroad, or from public or private research centers.
L'archive ouverte pluridisciplinaire HAL, est destinée au dépôt et à la diffusion de documents scientifiques de niveau recherche, publiés ou non, émanant des établissements d'enseignement et de recherche français ou étrangers, des laboratoires publics ou privés. 


\title{
Sen is not a capability theorist ${ }^{1}$
}

Antoinette Baujard ${ }^{2} \&$ Muriel Gilardone ${ }^{3}$

\begin{abstract}
This paper aims to clarify the status of capability in Sen's idea of justice. The name of Sen is so widely associated with the concept of capability that commentators most often assume that Sen's contribution to justice amounts to a capability theory, although underdeveloped. We argue that such reading is misleading. Taking seriously Sen's reluctance toward operationalization, we show that his contribution is inconsistent with a capability theory. Instead, we defend the idea of a heuristic role of the capability approach: capability is a step in the argument against alternative materials, but it is not meant as a definite end. Sen defends primarily a critical perspective to encourage public reasoning and respect agency on the definition of what should count for the evaluation of social states.
\end{abstract}

Key-words. Capability, capability theory, welfarism, justice, operationalization, paternalism, agency, public reasoning

JEL codes. A13, B41, D63, D79, 131

Word-count. 9812 words, 11126 words with abstract, notes and references

\section{INTRODUCTION}

"I have to rescue myself by saying [Sen says, thumping table] 'I'm not a capability theorist! For god's sake, I'm not a capability theorist'" (Sen in Baujard et al., in press ${ }^{4}$ ). The evident disagreement between Amartya Sen and his commentators regarding the status of capability is puzzling, and cries out for clarification of the role of capability in his theory of justice. According to a widespread reading, Sen's capability approach is the most important rival theory to Rawls' theory of justice as fairness, although it is still not yet developed to meet the basic requirements of a capability theory (Robeyns 2009: 397). Our paper questions this reading of Sen's contribution to theories of justice. The latter should not be interpreted as an underdeveloped capability theory; it instead leads us to revise our expectations regarding the role played by the material of justice in general, and more

\footnotetext{
${ }^{1}$ This research was made possible thanks to funding provided by CREM, and by a grant linked to the "Welfare Economics Chair" from Université Jean Monnet at Saint-Etienne and CNRS. The paper has been presented at the PHARE Seminar of Economic Philosophy (Paris, May 2014), at the $18^{\text {th }}$ meeting of the European Society of the History of Economic Thought (Lausanne, May 2014), and at the $2^{\text {nd }}$ International Conference for Philosophy and Economics (Strasbourg, October 2014). We wish to thank the participants at these events for their comments, including Catherine Audard, Emmanuelle Bénicourt, Constance Binder, Judith Favereau, and Bob Sugden. We are grateful to Béatrice Cherrier, Alain Marciano, Fabienne Peter, Philippe Solal, Alex Voorhoeve, and an anonymous referee for their comments on previous versions of the paper, and Ben Young for proofreading. We also thank Amartya Sen who, being aware of the paper and what it shows, kindly checked and accepted our using of certain quotes from the forthcoming conversation. The usual caveat holds.

${ }^{2}$ Université de Lyon, Université Jean Monnet, GATE L-SE UMR CNRS 5824, F-42 023 Saint-Etienne, France. Contact: antoinette.baujard@univ-st-etienne.fr

3 Normandie Université, UNICAEN, CNRS, CREM UMR CNRS 6211, 14000 Caen, France. Contact: muriel.gilardone@unicaen.fr

${ }^{4}$ This conversation has been transcribed in a paper for Social Choice and Welfare (Baujard et al., in press). See especially $20^{\prime} 20^{\prime \prime}-20^{\prime} 45^{\prime \prime}$ in the online movie "A conversation with Amartya Sen", Forge Numérique MRSH Caen, online since 06/07/2010, persistent address [URL: http://www.unicaen.fr/recherche/mrsh/forge/262].
} 
particularly by capability. In offering an explanation to Sen's refusal to be tagged as a capability theorist, we shall show that the commentators' misunderstanding is not simply due to Sen's view having evolved, but is more profound.

We claim that commentators may have been misled by some parts of Sen's discourse. Admittedly, Sen advocates a "social choice" approach to justice (Sen 2012a), and reports that he found social choice theory to be a true source of inspiration (Sen 2012b). Since justice issues are tackled in social choice theory by comparing different aggregation rules for individual welfares, justice is most often theorized through the framework of "formal welfarism": social welfare is the aggregation of individual welfares ${ }^{5}$, where a variety of definitions of welfare may be employed (e.g. Blackorby, Bossert and Donaldson, 2005). Within such framework, were Sen a capability theorist, he would first defend capability as the best definition of individual welfare -welfare being understood in a very broad sense-, propose a corresponding metric, and he would secondly consider the proper distributive rule independently. From this perspective, being a capability theorist amounts merely to defending a theory in which welfare is defined in terms of capability and the sole objects of public reasoning would be the prioritization of capabilities on the one hand, and the choice of a distributive rule on the other hand. We claim that such approach to justice divided in two stages is not only typical of social choice theory but also implicitly present in the general understanding of justice nowadays ${ }^{6}$. For instance, such view is relayed by philosophers such as Clare and Horn (2010: 75): "Sen's theory of comparative justice has two main aspects -the object or 'materials' of justice and the procedures for the comparative assessment justice [...] [which] must provide objective ways to assess the materials of justice". This is for us the reason why many commentators expect Sen to develop a capability theory of justice (e.g. Robeyns 2009, Robeyns and Brighouse 2010, Clare and Horn 2010, Shapiro 2011, Davis 20127\%).

We do not doubt that Sen's background in social choice theory is at the root of his contribution to theories of justice, nor that he played a prominent role in shifting the debate from a focus on aggregation to a focus on the informational basis for justice (e.g. Sen 1977). Indeed, Sen subsequently insisted that it was important to identify "how a person's interests may be judged and his or her personal state assessed" (Sen 1985b), and hence to debate whether alternative notions of well-being, preference, utility, or advantage can be adapted for discussions of justice and how they should be interpreted in specific contexts. Since Cohen (1989), the terms "metric" or "currency" of justice are often used for discussing the appropriate dimensions in which searching equality. Nevertheless, Sen seems careful to avoid such phrases, as a metric implies the possibility of "counting", aggregating, of quantitative assessment or comparisons, hence operational descriptions

\footnotetext{
${ }^{5}$ Aggregation should be here taken in its broadest sense, i.e a way to rank social states on the basis of the description of individual situations within these states. It includes two cases. First, we reduce the full description of each individual situation to a single collective outcome, e.g. with computing the sum of utilities in the utilitarian theory. Second, we rank the distributions of such states, e.g. following egalitarian or prioritarianist rules.

${ }^{6}$ In philosophical approaches, the second stage is often more complex than the mere definition of aggregative or distributive principles (see, for instance, the diverse modules of the cartwheel view in Robeyns (2016), once the material is chosen). But, what we claim is that the two stages are a minima present in philosophical theories of justice (see, e.g. Robeyns 2011).

${ }^{7}$ These references do not fall within the formal welfarism framework, but they share the idea that a theory of justice needs to propose a material which is a notion of the good relevant and adapted to the public realm.
} 
and mathematical properties (e.g. Sen 2009: 240). In contrast, Sen (2009) calls the concept used for an informational basis a "material", and indeed devotes a full part of his book to "the materials of justice". As we need to mark a sharp difference between a material and a metric to discuss the role played by capability in his contribution to justice, we will primarily focus on "material" in this paper.

Of course we do not wish to deny that Sen's reconsideration of the standard informational basis in economic theory led him to defend the view that capability constitutes a relevant material for justice as compared to utility (Sen 1980, 1985a, 1993, 2009). What we question, however, is the central role generally attributed to capability in Sen's idea of justice. Through a careful reading of Sen's works, this paper aims to demonstrate that capability is not the core of his theory of justice. In contrast, we consider that capability plays a purely heuristic role in Sen's framing of his theory of justice. According to the heuristic view that we advocate, Sen's position does not uphold the value of capability for its own sake; rather, Sen uses arguments in favor of capability in order to encourage public reasoning on the definition of what should count for the evaluation of social states, not to bring it to a definite end.

The paper is organized as follows. We firstly recall how and why Sen introduced the concept of capability (Section 1). Secondly, we present the debate regarding his underdeveloped capability theory of justice (Section 2). Thirdly, taking seriously his refusal to provide lists of capabilities, we establish that Sen is not a capability theorist, but a theorist of human agency and public reasoning (Section 3). Fourthly, we argue that capability may even be incompatible with Sen's conception of justice; this definitively undermines the capability-theory interpretation of Sen's work (Section 4). We complete the demonstration by showing that capability plays a heuristic role in Sen's view of justice: it is a step in a wider argument intended to open up the debate on justice, a debate that previously was limited to the aggregation problem within economics (Section 5).

\section{Context and motivation of Sen's capability approach}

(i) Since our purpose is to reveal the role played by the capability approach in Sen's contribution to the theories of justice, we will start by recalling the scientific context in which Sen introduced the concept of capability, as well as his motivations ${ }^{8}$. It is well known that Sen's development of the capability approach was originally motivated by a discontent vis-à-vis the informational poverty of welfare economics (e.g. Sen 1977 1980, 1999b; see also Gilardone 2010 and 2015 for an overview). From 1977 onwards, Sen developed a criticism of what he calls "welfarism," i.e. "[t]he general approach of making no use of any information about the social states other than that of personal welfares generated in them" (Sen 1977: 1559). More precisely, Sen defines welfarism by reference to two features: 1) the fact that well-being is identified by some subjective notion of utility, and 2) an

\footnotetext{
${ }^{8}$ For a precise definition of the capability approach, see Robeyns 2016. In reaction to Martha Nussbaum's description (Nussbaum 2011), she offers a less restricted characterization of both the core of the capability approach, and the ways it can be developed in a very wide range of more specific normative theories, under the common name of capabilitarianism. Robeyns' characterization is illuminating in many aspects, and paves the way for a diversity of usages and theories. Nevertheless, her characterization was not aimed to help in understanding the status of Sen's capability approach in his contribution to the issue of justice.
} 
exclusive focus on well-being for measuring social welfare (Baujard et al., in press). Sen rejects both features of welfarism because he considers us as individuals to be "agents' whose freedom to decide what to value and how to pursue what we value can extend far beyond our own interests and needs" (Sen 2009: 252).

In contrast, welfarism requires that we consider individuals merely as locations of utilities (Sen 1982a: 19). This conflicts with Sen's conception of individuals as agents, which appears through the intrinsic valuation of individuals' agency (e.g., Sen 1979, 1985a, 1993, 2006). An emphasis on agency considers individuals to be persons with the moral power to frame their own conception of the good. Because a focus on well-being is consequentialist, it is likely to violate agents' relative values, and hence to downplay agents' autonomy and deontology (Sen 1982b: 23). Imagine that utility was not exactly what a given individual thought should count for her well-being; or imagine that she pursued other goals apart from well-being, or had values which consisted in more than her own personal goals. In such cases, a welfarist policy conducted by some alien authority could favor her well-being but conflict with her agency.

(ii) For this reason, Sen introduces the concept of capability, and shows that it is a better candidate than utility to evaluate individuals' situation in this regard (e.g., Sen 1980, 1982b, 1984, 1985b, 1992, 1993a, 1999a, 1999b, 2006, 2009; see also Peter 2003 inter alia).

A capability is an opportunity set and it is specific to a person. Person i's "capability set [is] the set of functioning vectors within his or her reach" (Sen 1985b: 201), and among which this person will choose one particular functioning vector. Functionings refer to "various doings and beings that come into [the] assessment" (Sen 1985b: 197). For instance, a functioning vector would be the list: ( $i$ eats enough calories and calcium per day; $i$ has direct access to water; $i$ lives in her own house; $i$ sleeps on the floor; $i$ cannot read; ...); another functioning vector would be a similar list with different descriptions of each achievement, e.g., where $i$ can now read but does not live in her own house. Choosing one functioning vector rather than another implies choosing a kind of living. Valuing capability rather than functionings implies valuing i's choice of one kind of living per se - hence, freedom of choice rather than achievements. That is why we say capability stands for "the freedom to achieve actual livings that one can have reasons to value" (Sen 1999a: 73). Capability thus appears as a better candidate than utility if, in addition to well-being, we are to respect freedom and agency.

Since 1980, Sen has also insisted that his concept of capability is more relevant to defining the material of justice than Rawlsian primary goods. Although this comparison belongs to another line of argument than those regarding utility (see Robeyns and Brighouse 2010), it reinforces the idea that capability is a better material for justice. Capability takes into account the heterogeneous transformation rates of resources into what is valuable to each individual. Personal characteristics, as well as social or environmental factors that are not necessarily a person's responsibility, may greatly influence her ability to convert resources or primary goods into functionings, and hence her capability. For instance, if $i$ is pregnant, she will need more calories and more calcium per day than a non-pregnant woman: focusing on the goods of providing calories and calcium is not informative about how well fed this woman is, whereas the definition of functionings would focus on the achievements that are meaningful to her - "eat enough calories and calcium a day". The capability approach avoids "fetishism" of the goods (Sen 1980: 216), because it does not consider goods to be valuable in themselves, but only as regards what they enable individuals to be or to do.

Capability circumvents the drawbacks of utility or primary goods. It succeeds in focusing on what persons can do or be; and it avoids assigning intrinsic importance to something else, whether 
that is utility or resources. The defense of capability as a material for justice evaluation is typical of the capability approach.

\section{Sen's capability theory in question}

(i) Obviously, a capability theory of justice is more demanding than a capability approach tout court: beyond discussing the importance of a material of justice, it should be able to provide all the elements for assessing and comparing social states, and for deriving policy recommendations.

In the Stanford Encyclopedia of Philosophy, Robeyns (2011) elaborates on the additional characteristics that are needed for a capability approach to become a full capability theory of justice. According to Robeyns, a full capability theory of justice needs to explain: 1) the justification of the principles of justice it is based on, 2) whether it is an outcome or an opportunity theory, i.e. whether the theory is based on functionings or/and capabilities, 3) the specification of how to select, measure and aggregate dimensions, 4) the demonstration that the metric of capabilities is better than alternative metrics, 5) a position on the distributive rule that it endorses, e.g. whether it defends equality, sufficiency, prioritarism or any other mixed distributive rules, 6) the specification of the line between individual and collective responsibility.

(ii) Besides, there exists another perception of a capability theory of justice within contemporary welfare economics largely influenced by Sen's criticism of welfarism and utilitarianism. A theory of justice is generally presented in this field through the "formal welfarist framework" introduced by social choice theorists (e.g., Blackorby, Bossert and Donaldson, 2005). In the formal welfarist framework, social states are ranked on the basis of the assessment of social welfare, and social welfare results from the aggregation of individual advantages in the social state under consideration. The specificity of any theory of justice of this kind is thus captured by two distinct stages: the definition of individual advantage, i.e., of the relevant material for social justice, on the one hand; and the identification of one kind of distribution, on the other. The obtained ranking of social states is informative as regards the selection of a policy that fits the theory of justice being defined.

Formal welfarist theories of justice belong to a general family of theories of justice respecting these features. For instance, utilitarianism says that individual utilities are the appropriate measure of individual advantage, and the utilitarian social welfare function is the sum of all individual utilities. Hence the utilitarian theory of justice is characterized by the identification of a specific material at the individual level - utility - and by a specific form of aggregation of such individual utilities - the sum.

The formal welfarist framework focuses on two of the six characteristics put forward by Robeyns (2011) in the definition of a capability theory, namely point 3 and point 5 . In this perspective, a capability-theory of justice supposes capability is substituted for utility in the first stage because it captures a proper notion of individual welfare; it is then aggregated according a specific chosen rule of justice at the collective level, and from this we can derive a social welfare function (Blackorby, Bossert and Donaldson 2005, Iwata 2014, Fleurbaey and Blanchet 2013). A capability theory is totally defined once the two stages are defined. Firstly, one needs a measurable definition of capabilities, suitable to identify the elements of the functioning vectors or to specify a list of capabilities. Secondly, one needs to determine the distributive/aggregative rule, for example, should one maximize the sum of individuals' capabilities, use the leximin rule, etc.? 
It is fair to recall that the formal welfarist perspective is somewhat different from what is usually called "welfarism" in the literature, including in Sen's writings. It is indeed common to say that if the material is utility, then the theory is welfarist; conversely, using capability as an alternative material in a theory of justice is non-welfarist in this narrow sense. However, this non-welfarist focus is still compatible with the formal welfarist framework provided we respect the framing in terms of two stages.

(iii) It is then legitimate to ask whether Sen's theory of justice is indeed a capability theory of justice. Without going as far as considering the six characteristics to define a capability theory by Robeyns (2011), if we show that the association of Sen's idea of justice with just a subset of them is problematic, it shall be enough to consider that we have an issue: Is Sen really a capability theorist? Why is this so? Why the focus on capability is misleading? As we shall now show, these are clearly a matter of debate.

Sen's name is so widely associated with the concept of capability that many commentators assume that capability is central to his contribution to the theories of justice (e.g. Pressman and Summerfield 2002, Nussbaum 2003, Bénicourt 2007, Qizilbash 2007, Bonvin and Farvaque 2008, Robeyns and Brighouse 2010, Clare and Horn 2010, Shapiro 2011, Davis 2012, Ballet, Bazin, Dubois and Mahieu 2014). However, on this interpretation, Sen's capability approach stands in need of completion: commentators expect Sen to elaborate on most of the essential characteristics of a capability theory that we have just described, and they sourly complain about his silence in this regard. ${ }^{9}$

The first debate tackles the issue of selecting, quantifying and aggregating dimensions, and concretely to go from the choice of a material to the definition of a full metric. This concerns the third point highlighted by Robeyns (2011), requiring the operational identification of dimensions. The second debate focuses on the decision of a fully defined distribution rule to be used on concrete settings. For instance, Robeyns (2011) explains that "Sen has remained uncommitted to one single distributive rule", which indeed concerns the fifth point she highlighted, requiring the operational identification of distributive rules. At the end, the two debates happen to describe the two stages of the formal welfarist framework and they both derive from serious concerns with the operationalization of the capability approach.

(iv) Many commentators have offered damning judgments on the fact that Sen does not provide any elements with which to operationalize his capability approach (Sugden 1993, Nussbaum 2003, Robeyns 2003, Bénicourt 2007, Comim et al. 2008, Shapiro 2011). Some suppose he has just not taken the time and effort to do it, and propose to fill the blank themselves (Reboud 2005, Robeyns 2009, Robeyns and Brighouse 2010). Others question whether the concept of capability is useful at all, given that Sen himself does not offer a fully operational capability theory of justice. Bénicourt (2007: 66-67), for instance, regrets that Sen's illustrations of inequality or his evaluations of poverty are, oddly, often unrelated to his capability approach, and concludes the latter is simply otiose.

\footnotetext{
${ }^{9}$ See for instance Nussbaum (2003: 35): "the view is suggestive, but basically silent".
} 
Shapiro (2011) deplores that Sen did not use The Idea of Justice (2009) as an opportunity to develop his capability-based approach to justice. ${ }^{10}$

Let us elaborate on a representative instance of this line of thinking. Shapiro's expectations are characteristic of a formal welfarist reading: "Does it matter more that people have opportunities to realize existing capabilities or to develop undeveloped ones? Should we equalize the number of capabilities people have the chance to develop or perhaps the proportion of their capabilities that they can realize? Are some capabilities more important than others? Should the overall goal be to minimize unrealized capabilities?" (Shapiro, 2011: 1257). Were Sen a capability-theorist, there would indeed be no reason why he should stop his contribution at this point and leave aside what is now known as "the issue of operationalization".

(v) Contrary to expectations, Sen insists in not providing any description of the two stages: he refuses to provide a list of capabilities, nor does he provide any specification of how to aggregate individual capabilities into a collective evaluation. He pointedly leaves his capability approach underspecified, and defends this position as a principle (e.g. Sen 1993, 2004, 2005). So we cannot simply endorse the idea that Sen's capability theory is underdeveloped; rather, we should take Sen seriously the reasons why he refuses to provide a list or aggregative principles.

In interview, we asked him to respond to the related criticisms regarding operationalization. Sen is particularly vehement in this regard: indeed, the subject is clearly a matter of real irritation for him, given "what most people mean, when they come and ask how you're going to operationalize capability" (Baujard et al., in press). Sen not only refuses to provide definitive keys for the material and the aggregation issues; in fact, he does not consider the operationalization criticism to be relevant at all. He describes attempts at operationalization as a "category mistake", which demonstrates that commentators have seriously misinterpreted his idea of justice.

I don't know what 'operationalize' means. It is like saying, "Mr Mill, I understand what you are saying about liberty but how are we going to operationalize the demands of liberty? It was what Ryle would call a "category mistake". A subject like capability, it's not a formula, it's pointing towards a certain space. So it's like saying "How would you operationalize this space?" and I would say "Come again. What do you mean?" I'm saying this - the capability space - is a relevant space in a way that the utility space is not, the commodity space is not. That's it. I've operationalized it: I've told you what to look for. I don't have to end up by saying that the square root of the capability index obtained in this way has to be added to the cube root of something else. [...] That's what most people mean, when they come and ask how you're going to operationalize capability. I just say, "I don't really understand what the question is about". (Baujard et al., in press)

\footnotetext{
${ }^{10}$ Shapiro (2011), for instance, regrets that Sen does not resolve the trilemma raised in the "flute example" by means of his capability approach. In the flute example, we need to decide which of three children should get a flute: Anne, the one who knows how to play it; Bob, the poorest who has no other toys; or Carla, who made the flute. Sen (2009: 12-15) shows that the decision will differ depending on the material chosen - e.g. utility, resources, or effort, but surprisingly not capability all of which may be considered relevant.
} 
As we recalled in the introduction, he also spontaneously mentioned - thumping the table - that he was simply not a capability-theorist; and he insisted that you cannot "have a theory of justice based on capability only". He does not consider that an operationalization of his capability approach which corresponds, in our reading, to what is required in a formal welfarist framework - is what is missing to provide a full theory of justice: something else is missing, and we need to explore what that is.

\section{The inconsistency of Sen's idea of justice with a capability theory}

(i) In any capability theory of justice there must be, at least in principle, a list of capabilities (Robeyns 2011). Martha Nussbaum has developed a full theory of justice with a list of central and universal capabilities at its core. Inspired by Aristotelian philosophy, her list comprises all activities that prove necessary for a life to be truly human (Nussbaum 1999: 39). This constitutes a definition of the material of justice. She also provides a distributive rule when she claims that every individual should have access to all the capabilities on her list.

In contrast, the absence of list leaves the theory underspecified. Sen is conscious that framing a list of capabilities would be interpreted as the imposition of a comprehensive notion of the good life (e.g., Sen 1987, 1992: 82-83, 2004: 80, 2005: 159). Unlike Nussbaum, Sen refuses to assume the role of an Aristotelian philosopher. It would be problematic to endorse this role, because defending a theory which does not involve the participation of the agents concerned is likely to be paternalist.

While Robeyns (2009: 407) does not rule out a priori the possibility that capabilities may be selected without imposing a comprehensive notion of the good ${ }^{11}$, there has not been any proposal in this sense to our knowledge. For this reason, we are more inclined to share the view that, since a list of capabilities is required any capability theory must in the end be paternalist. This is what Carter (2014) defended. ${ }^{12}$ Accordingly he develops critical arguments that we interpret as follows. Consider two alternative functionings $x$ and $y-$ e.g., standing respectively for "having a job" and "taking care of your sick mother". Consider at least two agents $A$ and $B$ in a population: $A$, in charge of implementing a policy, has established a list of capabilities and has, for example, decided that $y$ is not valuable and that $x$ is valuable, such that $y$ is not part of this list, while $x$ is on the list. As a consequence, no policy shall promote the availability of $y$, while some policies shall promote the availability of $x$ to B. Through the better availability of $x$ and, as a corollary, the lesser availability of $y$, $B$ is encouraged to choose $x$ because of A's judgment on the situation, regardless of B's judgment. A is thus paternalist as regards to $B$, because $A$ is a stakeholder in the restriction of the list of capabilities while $B$ is not. The establishment of a restricted list of valued capabilities by an evaluator (e.g. a policy-maker) A is therefore paternalist towards B in this respect. All arguments to the effect that the capability approach is paternalist are based on the assumption of the existence of a list - in

\footnotetext{
${ }^{11}$ Notice paternalism is an issue both with consciously held notion of the good and with implicitly involuntary conveyed value judgments.

${ }^{12}$ Note that Carter speaks of the capability approach in general. But, insofar as he considers the existence of a list to be necessary, what Carter calls a capability approach is what we in this paper call a capability theory. In this regard, our view is consistent with the one of Robeyns (2016).
} 
our words, a capability theory is paternalist because it provides a well-defined list whether for justice evaluation or policy making.

We claim that these arguments are serious for capability theories, but are of little relevance for Sen's use of capability. Sen does not consider there exists a list, which is a necessary assumption for Carter's proof of paternalism.

Instead, Sen defends that solutions should take seriously how the evaluation of $x$ against $y$ is done and who, whether A or $\mathrm{B}$, is involved in the process of evaluation.

(ii) Let us first focus on Sen's argument as to how the process should be designed.

Operationalization would be an issue if the process were automatic: "'Operationalization' is a demand to get to solutions without thinking, without discussing, without debating", Sen says (Baujard et al., in press). Sen fears that a capability theory divided into two distinct and well-defined stages, would too easily be used as a substitute for reasoning, and to the consideration of any unusual but sometimes relevant information. He insists that such reasoning cannot be done once and for all, disregarding the context and the history of social deliberation:

Well, you have to ask what the relevant capabilities are and how you can have public reasoning about how to value them. And the public reasoning that happens in France may well be different from that elsewhere, given the history of the debate. It may favor, for example, state education in a way that the United States may not, and you could respect the reasoning in each case. I will not use the word 'operationalizing', I would say instead that in each case you will come out with a solution of some kind. I think this is a good system. (Baujard et al., in press)

Operationalization implies providing general solutions to identify the proper material; whereas in fact the material might differ in different situations. Sen refuses to fall into this trap: rather, he focuses on describing a process which will facilitate taking into account a wide range of information, engaging in thorough discussion, and reasoning in full about each single case. He uses the same kind of argument to explain his reluctance to join the search for a canonical list of capabilities, expressing his "disinclination to accept any substantive diminution of the domain of public reasoning" (Sen 2005: 157). He very explicitly insists on one central feature of his capability perspective: "to bring out the need for transparent valuational scrutiny of individual advantages and adversities" (Sen 2005: 157). He offers a broad interpretation of the capability approach, in which public reasoning takes priority over the material itself.

Thus, the novelty of Sen's idea of justice and his contribution to theories of justice is not exclusively concerned with the material of justice. Instead, it lies primarily in the character of the process we engage in to define this material.

(iii) In Sen's view, it also matters who is choosing (or participating in the choice of) the material.

If the individuals whose lives shall be assessed are part of the decision, the process is not paternalist. For instance, if in our previous example $A$ and $B$ are one and the same person, $B$ 's views will obviously be respected; while if $A$ is different than $B$ but asks $B$ to participate in the decisionmaking process, B's will is not violated. But if A alone is establishing a list that is to be applied to assess B's quality of life, then the process is indeed paternalist.

Sen wants to give individuals a voice in a way which circumvents the violation of agency and avoids paternalism. Agents should participate in determining their fate by being part of a process of 
public reasoning which is valued per se. Hence, his defense of capabilities cannot be judged paternalist; it does not conflict with the principle of equal respect for persons, i.e., with treating agents as ends in themselves (e.g., Carter 2014: 82, Dworkin 2014: 10). And such treatment shall not be reduced, for Sen, to looking at each person separately as a holder of a set of capabilities, like Robeyns (2016: 7) interprets it. Above all, it is meant to respect agency.

(iv) As a result, the meta-definition of justice for Sen does not depend on what is just or unjust, but on how and who participate in a process of collective decision. What is important in the process of the definition of the good life defended by Sen is how reasoning is valued in public decisions, and the particular involvement of individuals:

The connection between public reasoning and the choice and weighting of capabilities in social assessment is important to emphasize. It also points to the absurdity of the argument that is sometimes presented, which claims that the capability approach would be usable - and 'operational' - only if it comes with a set of 'given' weights on the distinct functionings in some fixed list of relevant capabilities. The search for given, pre-determined weights is not only conceptually ungrounded, but it also overlooks the fact that the valuations and weights to be used may reasonably be influenced by our own continued scrutiny and by the reach of public discussion. (Sen 2009: 242)

The use Sen makes of capabilities in social evaluation has always been conditioned by a "social choice exercise". And such an exercise should not be confused with what it means for standard social choice theory; it requires "public discussion" rather than aggregation of preferences. It is concerned with a search for "democratic understanding and acceptance", taking preferences as evolving to arrive at a "consensus" on weights - all the while allowing that this "democratic search for agreement [...] can be extremely messy" (Sen 1999a: 78-79).

A consequence of this argument is that Sen's contribution to the theory of justice should not be remembered for having provided a capability theory, but for something very different: a theory of human agency and public reasoning, both being intimately related in his view.

\section{The possible consistency of Sen's idea of justice with a material other than capability}

(i) Let us now provide a definitive argument in favor of the priority of public reasoning over capabilities. We will now show that the focus on capability itself is likely to be incompatible with Sen's idea of justice. In our view, the prominence of the debate on the difference between Sen and Nussbaum is responsible for having drawn too much attention to the list problem, and thus for hiding another essential element of Sen's position: the problem of there being any pre-established material at all.

This takes us back to the issue of paternalism, and to the related issue of the "container view", developed after the Rawlsian argument in favor of the separateness of persons (Rawls 1971: 26-27). If what is really being valued in a theory of justice is not the individual person $B$ per se, but just that $B$ is the container of $B^{\prime}$ s utility, then $B$ is not being treated as an agent nor as an end in itself. 
The same holds for any capability theory in which individuals are considered only through their capabilities. Like welfarism, the focus on capability violates Sen's idea of agency or equal respect of persons in so far as it is determined a priori that capability is the only material that will be counted. $B$, this time, will only be considered as the container of his own capability.

Imagine that an expert decides that capability is the proper material for a theory of justice. Once this is chosen, externally, the definition and the measure of capability are eventually decided through public reasoning, by including the persons who would be affected by the evaluation. The choice of the material, e.g. capabilities rather than utility, has still been imposed by some external expert and reflects her own general view of the good. This implementation thus does not involve agents in the definition of the proper notion of the good, and may not respect the actual aims that individuals have reasons to value. Hence, even with a reasonable participation of agents in the way capabilities are operationalized, the implementation of this capability approach may be incompatible with the core of Sen's idea of justice - at least as we perceive it.

(ii) As we noted in section 2, Sen (2009: 298) considers that, for moral reasons, rival reasoning or other criteria may have a role to play in the diagnosis of injustice. And this is not a new argument. In 1999 he explicitly developed the idea that the capability perspective always has to be compared with rival perspectives, if it is to be used fruitfully in public reasoning:

[...] since it is not claimed that the capability perspective exhausts all relevant concerns for evaluative purpose (we might, for example, attach importance to rules and procedures and not just to freedoms and outcomes), there is the underlying issue of how much weight should be placed on the capabilities, compared with any other relevant consideration. (Sen 1999a: 77)

Public reasoning over competing views is not a necessary component of a capability theory, but it has a key role to play in Sen's idea of justice, including in the definition of the material of justice. And Sen (1999a: 77) explicitly criticizes the exclusive focus on capability: "To insist on the mechanical comfort of having just one homogenous 'good thing' would be to deny our humanity as reasoning creatures"

(iii) Let us now confirm that the adoption of a material distinct from capability may still be compatible with Sen's idea of justice, in the sense we have here reconstructed.

Suppose that we have undergone a process of defining a material through the true participation of each agent in public reasoning. Now imagine that this deliberation has resulted in our picking the following alternative material: hedonist utility up to a certain threshold, in addition to freedoms. ${ }^{13}$ In a refined version of a similar idea, we value not only capability but also the actual utility associated with the functionings achieved thereby. In other words, such a material is a recipient of two distinct values, freedom and utility, captured respectively by capability and a certain valuation of functionings. This material does not coincide with capability per se, and attributing a

\footnotetext{
${ }^{13}$ A central claim from the freedom of choice literature is that it is impossible to attribute a value simultaneously to utility and to freedom. For a discussion of whether it is formally and conceptually possible to derive proper judgments over social states based on these two distinct values, see Baujard (2011). For an axiomatic description of one possible solution with threshold, see Baujard and Gaspart (2004).
} 
value to this material is not consistent with a strict capability theory in so far as capability unquestionably excludes the instrumental value of freedom - or, to put it differently, it excludes the intrinsic importance of utility (Fleurbaey and Blanchet 2013: 223-25). Yet there is a great deal of textual evidence to support the view that this example is likely to capture Sen's own values: he clearly attributes some importance to utility besides freedom - e.g., "The importance of freedom and of opportunity would be hard to motivate if the focus were not on the options or processes that one has reasons to value or want, but rather on alternatives one has no reason to seek" (Sen 2002: 5). Furthermore, Sen has sometimes mentioned "being happy" a possible achievement that people could value (e.g. Sen 2009: 276). And in this regard, it is clear for us that Sen does not consider that such subjective functioning should not be excluded a priori from the selection of the right material. ${ }^{14}$

With the proviso that this has emerged through a process in which each agent was fully involved in public reasoning, the focus on both utility and capability rather than on only the second is consistent with Sen's usual positions. A material distinct from capabilities may hence be compatible with the core of Sen's idea of justice.

(iv) It is clear to us that capability is insufficient to capture a notion of agency-freedom, since it requires taking into consideration "the process through things happen" (Sen 2002: 585), and not only the opportunity set available to each individual. In other words, if we take agency seriously, the processes by which agents reach social states may be crucial information for any evaluation. But Sen goes further in his account of agency-freedom, and, on our reading, this is the primary reason why we should see the core of his view of justice as rooted in public reasoning. Indeed, the importance of process and agency seems to fade away if agents are excluded from the process of decision-making as regards the evaluation of social states. We may thus claim that process should trump the focus on material.

\section{Arguments in support of the heuristic role of capability in Sen's idea of justice}

(i) One should now ask whether the misunderstanding between Sen and his commentators might, perhaps, be explained by an evolution in Sen's view regarding the role of capability in his argument. The 'evolution explanation' would assert the following: Sen was first envisaging a capability theory of justice, but realized in a second step that capability was vulnerable to criticism. In this story, commentators have become stuck on the first stage.

Yet it seems to us that the ambiguity of his presentation of the importance of capability is still evident in his later contributions. In The Idea of Justice, the concept of capability appears in the table of contents in the titles of the third part, devoted to "the materials of justice" - although it is worth mentioning that the use of the plural is here significant. Many pages are dedicated to defending the capability approach, and if we look more closely, he does use the expression "change of focus" (e.g.,

\footnotetext{
${ }^{14}$ This view contrasts with certain claims in the literature. According to Robeyns (2009: 407), while "being happy" may considered as a subjective capability, it should be a priori excluded from the selection of capabilities for it is not a legitimate ground on which citizens can make claims on each others in the public realm.
} 
Sen 2009: 254 , footnote), which does not amount to a commitment to a capability theory, although seemingly supports it.

Besides this, the focus on agency and public reasoning is already evident in Sen's first writings on the capability approach (e.g. Sen 1985a, see also below). Although it has become more clear in recent years, ${ }^{15}$ we will show that he introduced doubts about a capability theory from the very beginning (e.g. Sen 1980, 1999a).

As a result, we cannot accept that there is a sharp historical discontinuity regarding the status of capability in his writings. Rather, Sen is not a capability theorist who defends the unquestioned superiority of capability; and we propose a novel interpretation of the status of capability in Sen's account of justice which we call "the heuristic view". A heuristic device is an assumption provisionally adopted as a guideline, regardless of its absolute truth. According to the heuristic view we here defend, Sen's use of capability is simply a step in his argument against welfarism (or against resourcism). It is an argumentative step in a long demonstration which eventually issues in a theory of justice that does not fit formal welfarism - although this intention was not evident from the outset. There is, he argues, a better material for thinking about justice, namely capability; but this does not imply that capability is the best material, nor that it constitutes the complete guide for framing a theory of justice.

(ii) A first argument in favor of the heuristic view is based on textual proofs. The idea that the capability approach is above all a critical perspective regarding the material that is used for social evaluations is in fact present from the beginning. Sen's first introduction of the concept of capability was already clear in this regard:

This [rejecting the claims of utilitarian equality, total utility equality, and Rawlsian equality to provide a sufficient basis for the equality aspect of morality] is my main thesis. I have also made the constructive claim that this gap can be narrowed by the idea of basic capability equality, and more generally by the use of basic capability as a morally relevant dimension taking us beyond utility and primary goods. I should end by pointing out that the validity of the main thesis is not conditional on the acceptance of this constructive claim. (Sen 1980: 220, our italics)

This excerpt shows that Sen's main thesis in the first presentation of the capability approach was indeed to demonstrate the irrelevance of the welfarist framework. According to our reading, the concept of capability, set in opposition to utility as well as to Rawls's proposed alternative candidate, is an additional argument intended to undermine welfarism: there does exist a material that is more respectful of individual agency (see section I, ii). The same holds for his Dewey Lectures of 1984. If we take quotations out of context and ignore nuances, Sen certainly seems to express the view that capability and functionings are the best way to consider well-being (Sen 1985a: 195-203). But consider, now, the whole second lecture in which the demonstration is set out. The explicit aim of

\footnotetext{
${ }^{15}$ For instance, see Sen's explicit stance against interpretations of his work as a "capability-based theory of justice": "this could be true only in the rather limited sense of naming something according to a principal part of it" (Sen 2004: 337, footnote 38). More recently, he clearly distinguish "the fullness and the definitive achievements" of capability-based theories of justice such as Nussbaum's (1999) from "the informational perspective on which they are based" (Sen 2009: 232).
} 
this lecture is to propose a critical examination of the material of utilitarianism, which is supposed to show that utility is not an appropriate way to see well-being (Sen 1985a: 185). Capability offers an additional argument against such a welfarist approach: given that there exists a better material than utility, he remarks, the dominance of utility should be questioned. Such a critical role for the capability approach is again clearly stated by Sen:

In fact, the more challenging part of the claim in favour of the capability approach lies in what it denies. It differs from the standard utility-based approaches in not insisting that we must value only happiness [...], or only desire fulfillment [...]. It differs also from other - non-utilitarian - approaches in not placing among valueobjects primary goods as such, or resources as such [...]. (Sen 1993: 48)

More generally, Sen's aim is to question the most common materials proposed in theoretical approaches to justice, especially because they also have a certain echo in applied economics. Beside utility, resources are often taken as a good representation of individual advantage for distributive issues. Sen does sometimes present his capability approach as being particularly concerned with correcting the focus on means (e.g. Sen 1980, 1999b, Sen 2009).

(iii) Another argument in favor of the heuristic view is of a logical nature: better does not imply best. The widespread interpretation defends the claim that capability is the material which Sen suggests we should substitute for utility or resources in thinking about public policies and assessing social states. Sen himself (1999b: 358, 2009: 231) develops arguments supporting the idea that capability is an improvement of Rawls' proposal to judge individual advantage in terms of a person's command over primary goods, in order to move away from the utility perspective. This assertion does not have as a logical consequence that functionings or capabilities are good materials of justice, nor that they are the only suitable materials of justice. For instance, Sen (1980: 220) explicitly mentions that the introduction of the concept of capability allows him to do better than welfarist and ressourcist approaches, but not to solve the problem completely. From there, he specifies repeatedly that capability is something which proves to be better than utility in certain respects, and which avoids the failures of a resourcist framework (e.g. Sen 2009: 231-235): capability provides "a helpful perspective, in comparison with, say, the Rawlsian concentration on 'primary goods'" (Sen 2004: 337, our italics).

Nevertheless, Sen (1980) does not consider capability to be "the sole guide to the moral good": there could be other morally relevant claims to take into account in equality judgments, and also in other types of moral judgments of social states. "While it is my contention that basic capability equality has certain clear advantages over other types of equality, I did not argue that the others were morally irrelevant" (Sen 1980: 219-220). As asserted by Gilardone (2015), this significant qualification has largely been overshadowed by the innovation constituted by the introduction of the capability dimension. This is certainly at the source of misunderstandings between Sen and many of his commentators, in particular regarding the place devoted to capability in his idea of justice.

(iv) When Sen introduces capability, he never considers it as the only alternative to utility. There may be a plurality of relevant materials of which capability is only one. There might also be other information besides capability which would fit Sen's expectations.

More explicitly, Sen often mentions other relevant claims, such as that "one should not be exploited at work" or "equal pay for equal work" (e.g. Sen 1980: 213). In his Dewey Lectures (1985a), 
Sen makes a plea for plurality in assessing states of affairs. In the lecture he delivered after receiving the Nobel Memorial Prize in Economic Science, he also stresses that it would be "overambitious to be severely exclusive in sticking only to one informational approach, rejecting all others" (Sen 1999b: 359). And he does not hesitate to put to the fore other innovative informational inputs in applied welfare economics, such as expenditure patterns (whether alone or combined with other materials), regularities in people's answers to questionnaires, or observed features of living conditions (Sen 1999b: 359-360). In all these works it is evident he insists on a broadened understanding of individual advantage, and not only on the capability approach. What appears quite clearly in his Nobel Lecture is that he does militate in favor of capability evaluations, but admits and accepts that "others may well take a different view" (1999b: 360). His main point is that all views, including his, have limitations and virtues. This leads Sen to conclude that the relevance of a material depends on the context of evaluation and our priorities.

The same idea is manifest in the first Mahbub ul Haq Memorial Lecture of the Human Development and Capability Association (Sen 2008), in which he does not devote much space to capability. He highlights above all "the importance of looking at human lives themselves, rather than at the commodity possessions and other facilitating factors that have some influence over our lives" (Sen 2008: 334) and states that such an idea "has, by now, been much discussed in the literature and its implications have been widely explored in the contributions of many economists, social scientists and philosophers" (Ibid.). Indeed, the rest of Sen's lecture is devoted to other features of his idea of justice. This corroborates our heuristic view of Sen's capability approach, according to which it is designed to provide elements of a debate within welfare economics, and so to broaden its methods and objects via a better respect of individuals' agency.

(v) While Sen's earlier idea was to work on the informational basis of social choice and justice theories, he now recognizes that "it was soon clear that the approach could have a much wider relevance" (Sen 2009: 231). Once again, he refers to what was at stake in his Dewey Lectures. As already mentioned, Sen defends capability as a relevant notion of well-being as compared with utility: "a more plausible view of well-being is provided by the accounting of functioning vectors, refined by considerations of capabilities to function" (Sen 1985a: 221). But there is another important argument, though less remembered: he also aims to show that well-being is not relevant material for assessing states of affairs - "In this lecture, I have argued against accepting the adequacy of WAIF (well-being as informational foundation)" (Sen 1985a: 202). One reason for this is that the material of the moral approach should simultaneously include well-being and agency freedom (Sen 1985a: 221). When developing the issue of agency in the third lecture, he presents arguments about positional evaluations that would be central to the view of justice he defends in 2009 in relation to public reasoning, but does not mention capability at all. Nor does Sen elaborate on capability in a paper entitled "What Do We Want from a Theory of Justice?" (Sen 2006): this absence would be astounding on the capability theory reading, but makes sense on our heuristic view. He rather criticizes transcendental and contractarian theories of justice that offer a complete view of what is just; and he proposes instead a comparative theory of justice, which aims at assessing the advancement of justice, or the regression of injustice, on the basis of the plurality of viewpoints. Plurality is again related to positionality, and diverse positional viewpoints may refer to different kinds of information, all of which may be considered as relevant. The definition of the proper material of justice is clearly not presented as something we want from a theory of justice; Sen's 
argument concerns the procedural requirements of such a theory, i.e. "the reach and coverage of public participation" (Sen 2006: 216).

\section{Conclusion}

The goal of this paper was to state as definitively as possible what Sen's idea of justice is not: Sen's theory of justice is not a capability theory. We have shown that Sen does not suggest that we should simply substitute capability for utility, such that the dialectic stops there. There is simply no such thing as "Sen's metric". There is above all no attempt to move from the capability material to a capability metric.

We explained the misunderstanding between Sen and his commentators by the possible confusion induced by a reasoning within the box of capability theory. In particular, the formal welfarist framework is certainly influential on the way people think about theories of justice today, including regarding the role that a material like capability may play in a theory of justice. We claim that such a framework conditions the view that the core of Sen's idea of justice would be to support the focus on capability as the proper material of justice, while in a second step considering the issue of operationalization-including selecting the capabilities and the distributive rules-through a social choice exercise. This view is not only widespread, but indeed remains almost unquestioned. Sen himself has expressed regret that he has been "stuck" with the capability approach by his readers, and incorrectly tagged as a capability theorist. Nevertheless, it is also fair to say that Sen's writings are often confusing in this regard: the more profound proposal we feel he makes is too easily lost in the fog.

According to our reading, any focus on one ideal material would miss Sen's main point. We rather support a heuristic view on Sen's capability approach. For us, the status of capability in Sen's contributions to theories of justice is a heuristic device. The introduction of capability is an argumentative step in a long demonstration which eventually issues in a non-standard theory of justice. It aims at undermining both welfarism and resourcism, not at showing that capability is the only way or the proper way to think about justice. Sen also claims that well-being, even broadly understood, should not be the only concern of a theory of justice. The core of Sen's theory of justice most definitely lies elsewhere: it assigns an essential role to the process by which this material is defined, characterized by the involvement of the agents concerned in public reasoning. His defense of capability must be understood as a proposition to be discussed in such process. For him, the capability approach may indeed offer relevant perspectives on social states, but "its usability depends on the plausibility of seeing individual advantages in terms of capabilities" (Sen 1993: 50). Such plausibility needs to be judged within a framework of public reasoning and need not exclude all other materials.

As a result, Sen proposes a path-breaking relocation of justice: not only should we move beyond the aggregation issue, but we should also move beyond the issue of material. Human agency is so important in Sen's idea of justice that it leads him to leave open the definition of the good material, and each agent is responsible for elaborating this definition through a process of public reasoning. This represents an implicit, but devastating, criticism of the formal welfarist framework.

To a mind haunted by the specter of a capability theory, any presentation of Sen's idea of justice is likely to be misunderstood. Our aim in this paper was thus to undermine the widespread 
reading of Sen's idea of justice through the prism of a capability theory in order to propose a consistent basis for an alternative thinking about justice. Relocating his main contribution to the idea of public reasoning instead of the concept of capability is, for us, a necessary preliminary step for a fruitful discussion of his alternative theory of justice. ${ }^{16}$ In other words, public reasoning in Sen's idea of justice does not need to be focused on capability, and could well result in some other material of justice being valued.

To conclude, we remark that Sen's theory of justice is fundamentally democratic. His theory thus stands in opposition to a certain tendency in the academic community to hand all responsibility over to the community of philosophers and economists, tasked to define what welfare is or should be, to compute it and on this basis provide policy recommendations which are in line with the public interest so conceived. What Sen is striving to do - according to our reconstruction - is an important departure from the traditional framework of welfare economics: agents should be involved not just by voting for their representatives, but in the actual process of deciding how their lives should be evaluated and conducted. Subject to the proviso of our reading, Sen's theory is therefore a major contribution as regards the introduction of democracy into the realm of economic expertise and social welfare. However, the prism of the capability theory view is inhibiting fundamental and muchneeded progress in this sense. An obvious subsequent step would be the description and analysis of the link between human agency and public reasoning, thus further expounding Sen's actual theory by gaining closer insight into its content and its justificatory procedures. This cannot but be the subject of a distinct paper.

\section{References}

Ballet, J., Bazin D., Dubois J.-L. and Mahieu F.-R. (2014) Freedom, Responsability and Economics of the Person. Routledge, Frontiers of Political Economy: London and New York.

Baujard, A. and Gaspart, F. (2004) Opportunity and equity in economic environment. WP CREM-Caen. Baujard, A. (2011) Utilité et liberté de choix dans les classements d'ensembles d'opportunités, Raisons politiques, 43: 59-92.

Baujard, A., Gilardone, M. and Salles, M. (forthcoming) A Conversation with Amartya Sen. Social Choice and Welfare (Based on the 2010 interview in Harvard University).

Blackorby, C. W. Bossert and D. Donaldson, (2005) Multi-profile welfarism: a generalization, Social Choice and Welfare, 25(1): 227-228.

Bénicourt, E. (2007) Amartya Sen : un bilan critique. Cahiers d'économie Politique / Papers in Political Economy, 52, 1: 57-81.

\footnotetext{
${ }^{16}$ To a certain extent our analysis echoes Qizilbash's (2007) distinction between thick and thin views on the capability approach. Qizilbash (2007: 170) calls a "thin view" on the capability approach "arguments in favor of capability and functioning as significant evaluative spaces"; and he defines the "thick view" as arguments which stress the importance of public reasoning for dealing with the evaluative issues that arise in the application of the capability approach. According to us, it is correct that public reasoning is at the core of Sen's theory of justice. However, we show that this has no necessary relation to an application of the capability approach.
} 
Bonvin, J.-M. and Farvaque, N. (2008) Amartya Sen. Une Politique de la Liberté. Paris : Michalon. Carter, I. (2014) Is the capability approach paternalist? Economics and Philosophy, 30,1: 75 - 98.

Clare, J. and Horn, T. (2010), Sen and Sensibility, South African Journal of Philosophy, 29, 2: 74-84.

Cohen, G. (1989), On the Currency of Egalitarian Justice, Ethics, 99, 4: 906-944.

Comim, F., Qizilbash, M. and Alkire, S. (Eds.) (2008) The Capability Approach. Concepts, measures and applications. Cambridge: Cambridge University Press.

Davis, J. (2012) The idea of public reasoning. Journal of Economic Methodology, 19, 2: 169-172.

Dworkin, G. (2014) Paternalism. The Stanford Encyclopedia of Philosophy, Summer 2014 Edition, Edward N. Zalta (ed.): http://plato.stanford.edu/archives/sum2014/entries/paternalism/

Fleurbaey, M. and Blanchet, D. (2013) Beyond GDP. Measuring welfare and assessing sustainability. New-York, NY: Oxford University Press.

Gilardone, M. (2010) Amartya Sen sans Prisme. Cahiers d'économie Politique / Papers in Political Economy, 58 : 9-39.

Gilardone, M. (2015) Rawls's influence and counter-influence on Sen: Post-welfarism and impartiality. The European Journal of the History of Economic Thought, 22, 2: 198-235.

Iwata, Y. (2014) On the informational basis of social choice with the evaluation of opportunity sets, Social Choice and Welfare, 43, 1: 153-172.

Nussbaum, M. (1999) Sex and Social Justice. Oxford: Oxford University Press.

Nussbaum, M. (2003) Capabilities as Fundamental Entitlements: Sen and Social Justice. Feminist Economics 9, 2-3: 33 - 59.

Nussbaum, M. (2011) Creating Capabilities: The Human Development Approach. Cambridge, Mass.: The Belknap Press of Harvard University Press.

Peter, F. (2003) Gender and the Foundations of Social Choice: The Role of Situated Agency. Feminist Economics 9, 2: 13-32.

Pressman, S. and Summerfield, G. (2002) Sen and Capabilities. Review of Political Economy, 14, 4: 429-433.

Qizilbash, M. (2007) Social Choice and Individual Capabilities. Politics, Philosophy \& Economics 6, 2: 169-192.

Rawls, J (1971) A Theory of Justice. Oxford: Oxford University Press.

Reboud, V. (2005) What could a capability-based policy be? Cahiers de Recherche CREM, Université de Caen.

Robeyns, I. (2003) Sen's capability approach and gender inequality: selecting relevant capabilities. Feminist Economics, 9, 2-3: 61-92.

Robeyns, I. (2009) Justice as Fairness and the Capability Approach. In K. Basu and R. Kanbur (Eds.) (2009) Arguments for a Better World. Essays in Honor of Amartya Sen, Oxford: Oxford University Press: 397-413.

Robeyns, I. and Brighouse, H. (2010) Introduction: Social primary goods and capabilities as metrics of justice. In Robeyns, I. and Brighouse, H. (Eds.) (2010) Measuring Justice: Primary Goods and Capabilities, Ch. 1: 1-13. Cambridge: Cambridge University Press.

Robeyns, I. (2011) The Capability Approach, The Stanford Encyclopedia of Philosophy, Summer 2011 Edition, Edward N. Zalta (ed.): http://plato.stanford.edu/entries/capability-approach/

Robeyns, I. (2016) Capabilitarianism, Journal of Human Development and Capabilities, 17: 397-414.

Sen, A.K. (1977) On Weights and Measures: Informational Constraints in Social Welfare Analysis, Econometrica, 45, 7: 1539-1572.

Sen, A. K. (1979). Utilitarianism and welfarism. The Journal of Philosophy, 76, 9:463-489. 
Sen, A.K. (1980) Equality of What? The Tanner Lecture on Human Values Delivered at Stanford University (May 22, 1979) Cambridge: MacMurrin.

Sen, A. K. (1982a) Choice, Welfare and measurement, Oxford, Basil Blackwell or Cambridge Mass., MIT Press.

Sen, A. K. (1982b) Rights and agency. Philosophy \& Public Affairs, 11, 1: 3-39.

Sen, A. K. (1984) The Living Standard, Oxford Economic Papers, 36: 74-90.

Sen, A. K. (1985a) Well-being, agency and freedom: The Dewey Lectures 1984. The Journal of Philosophy 72, 4: 169-221.

Sen, A. K. (1985b) Commodities and Capabilities. Delhi: Oxford University Press.

Sen, A. K. (1987) The Standard of Living: Lecture II, Lives and Capabilities. In Hawthorn, G. , The Standard of Living, Cambridge, Cambridge University Press, 20-38.

Sen, A. K. (1992) Inequality Re-Examined. Oxford: Clarendon Press.

Sen, A. K. (1993) Capability and well-being. In Nussbaum, M. C. and Sen, A. K. 1993. The Quality of Life. Clarendon Press, Oxford, Edition 2001: 30-53.

Sen, A. K. (1999a) Development as Freedom. Oxford: Oxford University Press.

Sen, A. K. (1999b), The Possibility of Social Choice. American Economic Review, 89, 3: 349-378.

Sen, A. K. (2002) Rationality and freedom. The Belknap Press of Harvard University Press: Cambridge, Massachusetts \& London, England.

Sen, A. K. (2004) Capabilities, Lists and Public Reason: Continuing the Conversation. Feminist Economics, 10: 77-80.

Sen, A. K. (2005) Human rights and capabilities. Journal of Human Development, 6, 2: 151-166.

Sen, A. K. (2006) What do we want from a theory of justice? Journal of philosophy, 103, 5: 215-238.

Sen, A. K. (2008) The Idea of justice. Journal of Human Development, 9, 3: 331-342.

Sen, A. K. (2009) The Idea of Justice. Cambridge MA: The Belknap Press of Harvard University Press.

Sen, A. K. (2012a), "Values and Justice", Journal of Economic Methodology, 19 (2): 101-108.

Sen, A. K. (2012b), "The Reach of Social Choice Theory", Social Choice and Welfare, 39 (2-3): 259-272.

Shapiro, I. (2011), "Review of The Idea of Justice, by Amartya Sen", Journal of Economic Literature, 49 (4): 1251-1263.

Sugden, R. (1993) Welfare, resources and capabilities: A review of 'inequality reexamined' by Amartya Sen. Journal of Economic Literature 31: 1947-1962. 